\title{
Emergency Nurses' Suggestions for Improving End-of-Life Care Obstacles
}

\author{
Renea L. Beckstrand \\ Brigham Young University - Provo \\ R. Daniel Wood \\ Brigham Young University - Provo \\ Lynn C. Callister \\ Brigham Young University - Provo \\ Karlen E. (Beth) Luthy \\ Brigham Young University - Provo, beth_luthy@byu.edu \\ Sondra Heaston \\ Brigham Young University - Provo \\ Follow this and additional works at: https://scholarsarchive.byu.edu/facpub \\ Part of the Critical Care Nursing Commons, and the Other Nursing Commons
}

\section{Original Publication Citation}

Beckstrand, R. L., Wood, D.**, Callister, L. C., Luthy, K. E., \& Heaston, S. (2012). Emergency

nurses' suggestions for improving end-of-life care. Journal of Emergency Nursing, 38(5), e7-e14.

\section{BYU ScholarsArchive Citation}

Beckstrand, Renea L.; Wood, R. Daniel; Callister, Lynn C.; Luthy, Karlen E. (Beth); and Heaston, Sondra, "Emergency Nurses' Suggestions for Improving End-of-Life Care Obstacles" (2012). Faculty Publications. 5238.

https://scholarsarchive.byu.edu/facpub/5238

This Peer-Reviewed Article is brought to you for free and open access by BYU ScholarsArchive. It has been accepted for inclusion in Faculty Publications by an authorized administrator of BYU ScholarsArchive. For more information, please contact ellen_amatangelo@byu.edu. 


\title{
EMERGENCY NuRSES' SUGgeSTIONS FOR IMPROVING END-OF-LIFE CARE OBSTACLES
}

\author{
Authors: Renea L. Beckstrand, PhD, RN, CCRN, CNE, R. Daniel Wood, BS, Lynn C. Callister, PhD, RN, FAAN, \\ Karlen E. Luthy, DNP, FNP-C, and Sondra Heaston, FNP-c, APRN, Provo, UT
}

Introduction: More than 123 million ED visits are reported annually. Many patients who arrive for care to help extend their lives instead die while in the emergency department. Emergency departments were designed to save lives rather than to provide optimal end-of-life (EOL) care. Emergency nurses care for these dying patients and their families. The purpose of this study was to determine what suggestions emergency nurses have for improving EOL care.

Methods: Emergency nurses were asked which aspects of EOL care they would like to see changed to improve how patients die in emergency departments. Of the 1000 nurses surveyed, 230 provided a total of 295 suggestions for improving EOL care. Content analysis was used to identify categories of qualitative responses. Responses were coded individually by research team members and then compared with ED EOL literature. Clusters of data were formulated to form themes with sufficient data returned to reach saturation.
Results: Five major themes and four minor themes were identified. The major themes were increasing the amount of time ED nurses have to care for dying patients, allowing family presence during resuscitation, providing comfortable patient rooms, providing privacy, and providing family grief rooms.

Conclusion: Large numbers of patients seek care in emergency departments. Emergency nurses are often called on to care for dying patients and their families in this highly technical environment, which was designed to save lives. Emergency nurses witness the obstacles surrounding EOL care in emergency departments, and their recommendations for improving EOL care should be implemented when possible.

Key words: End-of-life; Emergency; Emergency nurse; Obstacles; Family presence
$\mathrm{D}$ eath is not an uncommon outcome for patients who seek immediate care in an emergency department. In 2006, more than 249,000 patients died in the emergency department or were reported as being dead on arrival at the emergency department. ${ }^{1}$ Because of the high number of deaths in emergency departments,

Renea L. Beckstrand is Associate Professor, College of Nursing, Brigham Young University, Provo, UT.

R. Daniel Wood is Graduate Student, FNP Program, College of Nursing, Brigham Young University, Provo, UT.

Lynn C. Callister is Emeritus Professor, College of Nursing, Brigham Young University, Provo, UT.

Karlen E. Luthy is Assistant Professor, College of Nursing, Brigham Young University, Provo, UT.

Sondra Heaston is Associate Teaching Professor, College of Nursing, Brigham Young University, Provo, UT.

For correspondence, write: Renea L. Beckstrand, PhD, RN, CCRN, CNE, PO Box 25432, 422 SWKT, Provo, UT 84602; E-mail: renea@byu.edu.

J Emerg Nurs 2012;38:e7-e14.

Available online 22 June 2012.

$0099-1767 / \$ 36.00$

Copyright (C) 2012 Emergency Nurses Association. Published by Elsevier Inc. All rights reserved.

doi: $10.1016 /$ j.jen.2012.03.008 emergency nurses often are called upon to provide endof-life (EOL) care for dying patients and their families. However, the emergency department is a difficult location for patients, family members, and clinicians to make EOL decisions and for health care providers to give appropriate EOL care. The ED environment makes EOL decisions increasingly difficult for all persons involved because of time constraints, lack of patient and family privacy, communication challenges, lack of accessibility of patient information to health care providers, and societal expectations regarding emergency care. ${ }^{2}$

\section{Background}

Emergency departments are becoming increasingly busy; in 2008, 123.8 million ED visits were reported across the United States. ${ }^{3}$ High patient volume is further complicated by a decreasing number of emergency departments, as well as the fact that the emergency department is becoming the portal for inpatient admissions, accounting for $50.2 \%$ of nonobstetric admissions nationally. ${ }^{1}$ Many patients seeking ED care have advanced chronic illness that requires immediate aid for symptom distress, are experiencing acute change in their health status, or are brought to the emergency department by their caregivers who can no longer 
physically care for or psychologically cope with these sick family members. ${ }^{4}$

As in many other critical care areas of the hospitals, heroic measures often are expected in the emergency department. Patient care plans that include only comfort measures or withholding and even withdrawing medical treatments are viewed as traumatic decisions for most ED clinicians and require an enormous amount of effort to implement. ${ }^{5}$ Because emergency nurses provide most of the EOL care in emergency departments, they witness obstacles that inhibit EOL care and behaviors that improve EOL care for dying patients and their families on a daily basis. ${ }^{6,7}$

Although death is a common occurrence in the emergency department, the literature provides little information regarding EOL care. McClain and Perkins ${ }^{8}$ gave an overview of EOL challenges that commonly are associated with caring for terminally ill ED patients, including pain control, dyspnea, fatigue, delirium, and dehydration. Le Conte et $\mathrm{al}^{9}$ completed a prospective study regarding the withholding and withdrawing of life-support therapy in an ED setting that demonstrated poor participation of both patients and nurses in the decision-making process. Chan ${ }^{10}$ found that little is known regarding EOL ED care and that most EOL models are developed for more chronic disease processes in which the trajectory is known and predetermined. Therefore these predetermined models do not fit sudden illness, injury, or acute exacerbation of a chronic illness as is often seen in emergency departments.

Quest ${ }^{11}$ reported the vulnerability that patients may feel when their providers do not understand their cultural and spiritual uniqueness while helping the patient make health care decisions. Language barriers and cultural/ spiritual/religious differences need to be overcome to reduce the vulnerability of patients and families in emergency departments.

$\mathrm{Li}$ et $\mathrm{al}^{12}$ reported the nursing actions that suddenly bereaved family members viewed as helpful, including providing written information, enabling the family to view the deceased, respecting individual customs, and honoring religious procedures. Heaston et $\mathrm{al}^{7}$ surveyed a national sample of 300 emergency nurses and identified perceptions of common obstacles and supportive behaviors that emergency nurses encounter while providing EOL care. Beckstrand et $\mathrm{al}^{6}$ sampled 700 emergency nurses and then reported the size, frequency of occurrence, and magnitude of both obstacles and supportive behaviors of providing EOL care in emergency departments.

\section{SUMMARY}

Emergency nurses are on the front line of caring for dying patients and their families. Because little research has been published regarding emergency nurses' perceptions of possible ways to improve EOL care in emergency departments, the purpose of this research study was to determine what changes emergency nurses would suggest to improve EOL care for dying patients and their families.

\section{RESEARCH QUESTION}

The report of the qualitative portion of this mixed method study builds on other research documenting emergency nurses' perceptions of the obstacles to providing EOL care in emergency departments. ${ }^{6,7}$ However, these research reports focused only on the qualitative results of one item on the questionnaire sent to the entire sample. Therefore a need was identified to report the valuable qualitative data from the emergency nurses providing EOL care that were gathered in the previous studies. Consequently, the openended research question was, "What aspects of EOL care would emergency nurses change to improve how patients die in an emergency department?"

\section{Methodology}

After institutional review board approval was obtained for this mixed methods study, a questionnaire entitled "Emergency Nurses' Perceptions of End-of-Life Care" was sent to a national, geographically dispersed, random sample of 1000 emergency nurses.

The first phase of the study included a subset of 300 randomly selected emergency nurses from the original purchased list to pilot the new instrument. ${ }^{7}$ Three mailings were completed to nonresponders. Once the pilot study was completed, the second phase of the study began, with questionnaires mailed to the remaining 700 nurses. The second phase included frequency of occurrence information for each obstacle or supportive behavior item, and the questionnaire was mailed up to 3 times to nonresponders. ${ }^{6}$ Quantitative data from the 2 phases of this research study have been published previously. 6,7

The open-ended question answered for this report was, "If you had the ability to change just one aspect of the EOL care given to dying ED patients, what would it be?" This item was identical on all 1000 questionnaires. Data from this one question, gathered during both phases of the research study, have been combined here so that results from the larger sample of emergency nurses could be presented.

Sample inclusion criteria included nurses who were members of ENA, could read English, worked in an emergency department, and had cared for at least one dying emergency patient. All responses were entered into a database. Four different nurse experts, including a qualitative nurse researcher, a critical care nurse researcher, an 
TABLE 1

Demographics $^{a}$

\section{Characteristics}

Gender

Female

Male

Age (y)

Years as registered nurse

Years in ED

Hours worked/wk

No. of beds in ED

Years as CEN

No. of dying patients cared for

$>30$

21-30

11-20

5-10

$<5$

Mean

Standard deviation

Range

$\%$

96

85.2

34

14.8
46

20.1

14.5

27.8

27.1

9.8
9.5

10.6

8.9

13.8

14.7

6.7
$25-71$

$1-45$

$1-40$

$0-75$

$0-76$

$.3-26$

Highest degree

Diploma

Associate

Bachelor

Master

Doctoral

Ever certified as CEN

Yes

No

Currently CEN

Yes

No

Practice area

Direct care/bedside nurse

Staff/charge nurse

Clinical nurse Specialist

Other (eg, manager, educator)

Hospital type

Community, nonprofit

Community, profit

County hospital

Other

16.4

CEN, Certified emergency nurse; $E D$, emergency department

${ }^{a} \mathrm{~N}=1000 ; 441$ returned; $\mathrm{n}=230(52 \%)$ responded to this item for 295 total suggestions. 
TABLE 2

\section{Major and minor themes ${ }^{a}$}

\section{Major themes}

1. Increase time and availability ED nurses have to care for dying patients and their families $(n=76)$

2. Consistently allow family presence during resuscitation ( $\mathrm{n}=41)$

3. Provide a comfortable patient room $(\mathrm{n}=34)$

4. Provide for more privacy at the end of life $(n=32)$

5. Provide a family grief room $(n=20)$

\section{Minor themes}

1. Increase support and involvement from ancillary staff $(n=16)$

2. Minimize patient suffering by managing pain $(\mathrm{n}=14)$

3. Improve education to the family regarding end-of-life care $(n=13)$

4. Uphold advance directives and follow the patient's wishes $(\mathrm{n}=11)$

${ }^{a}$ Major themes had more than 20 responses. Minor themes had $\leq 16$ responses.

advanced practice nurse with more than 20 years of emergency nursing experience, and a graduate student who was an emergency nurse, individually reviewed and coded each returned response. Content analysis was used to identify categories of qualitative responses. Open-ended survey responses were read individually by research team members and compared with the ED EOL literature, which, when coded, showed an inter-rater reliability of .98 between reviewers of the narrative data. Clusters of data were formulated to form themes supported by "data bits." Sufficient data were returned to reach conceptual saturation, with rich statements supporting each theme. ${ }^{13,14}$

\section{Results}

Questionnaires were returned from 441 emergency nurses from across the United States. Of nurses who returned questionnaires, $230(52 \%)$ wrote a response to the specified item in which they offered one or more suggestions. Although each of the 230 nurses was asked to report just one aspect of EOL care they would like to change, 47 nurses gave multiple suggestions for change, resulting in 295 total suggestions.

Emergency nurses who provided suggestions for improving EOL care in the emergency department were 23 to 71 years old $(M=46$ years, $S D=9.5)$. Of those responding to gender, 196 were female $(85.2 \%)$ and 34 were male $(14.8 \%)$. Additional demographic information is provided in Table 1 .

\section{MAJOR THEMES}

Overwhelming consistency was found in the changes that nurses participating in the study recommended to improve care of dying ED patients. Five major themes were identified: (1) increasing the amount of time and the availability ED nurses have to care for dying patients and their families; (2) consistently allowing family presence during resuscitation; (3) providing a comfortable patient room; (4) providing for more privacy at the EOL; and (5) providing a family grief room. Table 2 summarizes the major and minor themes.

\section{Increased Registered Nurse Time With the Patient and Family}

Emergency nurses recognized that effectively delivering EOL care requires time and a consistent presence in order to help educate and support family members. Nurses described a desire to change the quality and consistency of this last family interaction by recommending, "The ER RN [should] have the time to spend with the family of a dying patient, not a run-in and run-out type of care." Several respondents echoed this nurse's comment; one recommended that nurses "Have more involvement with the family and [have the] opportunity to express condolences [and] give comfort in simple ways."

ED nurses also reported that staffing limitations plus the nursing needs of other patients decreased their ability to provide optimal care to dying patients. One nurse said, "[There needs to be enough] staffing that allows me to do it right. I know what to do; too bad I'm not given the time." Several nurses recommended specifically that the nurse be able to give one-to-one nurse to patient care at the EOL to meet the many demands associated with this transition. One nurse responded, "Free me of responsibility for other patients to facilitate my providing uninterrupted care for [the] dying patient and their family." One nurse hoped to "Make EOL patients a 1:1 ratio to allow ample time to ease the patient to death's door with dignity while supporting the family."

\section{Family Presence}

Emergency nurses overwhelmingly recommended that they would improve ED EOL care by connecting patients with 
their family members rather than separating them at this critical time. Emergency nurses expressed a desire to have a hospital policy enabling family presence during EOL and that the policy be implemented on a consistent basis. Family involvement in EOL care was also emphasized by one ED nurse, who stated, "Make sure families are involved and informed of what is being done and what will be happening. You must include family, not exclude family, at these times." Another nurse further articulated the importance of family involvement by stating, "I would bring family members in during resuscitative efforts so they could be part of the end-of-life team." One nurse who worked in a 76-bed emergency department recommended there be a "Hospital policy regarding allowing family in the room during resuscitation efforts; instead of [family presence] being [implemented] haphazardly." Finally, one respondent hoped to "Give [the patient] and their family a chance to see and hear and touch [each other] during their last moments; to know that [the family's] presence was felt [by the dying patient].”

\section{Comfortable Patient Room}

Many respondents believed that creating a place of comfort should be the priority in providing EOL care in the emergency department. One nurse wrote, "Our ED rooms are so cold feeling; [the dying patient] needs a peaceful place." Another nurse stated that a private area is needed, "...so that the family can experience this part of the patient's life with dignity, support, privacy and compassion." One nurse expressed a desire to "Have a special room for the patient with a room for the family connected and have décor more like home, less institutional appearing." Another respondent requested a "Better architecturally planned ED to allow for enhanced privacy and room for the dying patient and family."

Responses also addressed concern for patients who were sharing space in close proximity to a dying patient: "We do our best to provide as much privacy and support as we can, but often in a room for two patients [with] a curtain between them [it's] very hard for [those on] the other side of the room." This concern is also connected to the next most common concern of privacy issues.

\section{Providing More Privacy}

The recommendation for improved privacy for dying patients and their families was the fourth most mentioned EOL care issue. In addition to providing a room for family members to grieve, nurses suggested changes to patient care rooms to improve the experience for both the family and dying patient. One nurse responded, "[We need] better provisions for grieving, better rooms and rooms that are only [used] for this purpose." Several nurses recommended having areas set off that were quieter, with one nurse noting that in the emergency department, "Even though [the dying patients and their families] are in a separate room, everyone in the ED knows what is happening." Several nurses expressed their belief that providing privacy might not be possible in a busy emergency department and recommended attempting to move the patient and family members to an area outside the emergency department.

\section{Family Grief Room}

The hectic pace and close quarters typical of an ED environment can be an uncomfortable setting for grieving family members who are supporting a dying patient. Many respondents suggested that access to a "grief room" in the emergency department might improve this environmental problem. Their recommendations included, "For our small $\mathrm{ED}$ it would be nice to have a room or private area for the family to use during this difficult time." Another nurse recommended, "Provide an additional private, quiet environment for the family, physicians, clergy, and other support personnel to communicate and make decisions."

\section{MINOR THEMES}

Four other themes also were identified, but whereas the major themes were all mentioned by 20 or more respondents, each of the minor themes was mentioned by 16 or fewer emergency nurses. These four themes included increasing support from and involvement of ancillary staff; minimizing suffering by managing pain; improving education to the family regarding EOL care; and upholding advance directives and patient wishes.

\section{Increased Ancillary Service Involvement}

Suggested methods for providing improved EOL care to the patient and family included nonpharmaceutical interventions and increased involvement from ancillary services. One nurse recommended "[Having] ancillary staff at every facility (even small ones) [that] can contact people for families, pastoral care, social services etc." Frustration was evident as this respondent recommended, "More help to deal with the family so I can focus on the patient [and] not have to be a social worker. Chaplains and social workers are not always available and I do not have the time or inclination to care for family needs during [the] grieving process."

\section{Managing Pain and Minimizing Suffering}

Providing better pain control for dying patients was an emphasis for many nurses. A nurse with more than 11 years of emergency nursing experience who works in a 60-bed emergency department recommended, "Provide more comfort with decreased procedures and increased 
pain medication. Comfort medications should never be withheld due to side effects that may hasten death (hypotension, [decreased] respiration etc.)." Another respondent stated, "I wish we weren't a society afraid of administering adequate doses of pain medications. We often fear we could suppress their respiratory effort when death is imminent anyway." This respondent summarized the optimal goal best when saying, "I would increase the amount and frequency of pain medications given to the dying patient to meet their actual needs regardless of outcome."

\section{Family Education}

Respondents consistently emphasized the importance of educating patients and families regarding EOL care and expectations. A nurse with 8 years of emergency experience suggested, "Educate the family to the client's illness before the client goes to the emergency room [and] also discuss what an advance directive and DNR is before the situation happens, to make that decision easier on everyone." Another nurse hoped the following question would be asked to family members: "I would ask them, do you really feel your loved one would want to be kept alive this way?"

\section{Upholding Advance Directives}

Nurses suggested that patient's desires and wishes at the EOL be honored. One nurse hoped to "[Know] the patient's wishes up front. We often do not have rapid access to documents when they exist, and many patients have no documentation of their wishes." Even with appropriate documentation available, supporting the patient's EOL decisions can be difficult for family. Other respondents emphasized respecting the patient and their decision: "Support the patients' EOL wishes/decisions even though the family is [not] sure." One nurse encouraged, "Let patients die with peace and dignity when it is their wish that no extreme measures be taken."

\section{MISCELLANEOUS RESPONSES}

In addition to the 5 major themes and 4 minor themes that emerged from the data, many responses were categorized as miscellaneous $(n=39)$. Several nurses articulated the difficulty in choosing one specific aspect of ED EOL care to change. For example, one emergency nurse with more than 10 years of emergency experience said, "Each situation is unique. It's difficult to generalize [because] there are so many contributing factors, for example, staffing, how busy the department is, space, and how much time the dying patient has." Additional suggestions included improving physician communication with the patient and family, improving staff education regarding EOL care, providing a "good death," and improving critical debriefings after a patient's death.

\section{Discussion}

These results contribute to the body of knowledge that emergency nurses recognize as deficiencies in ED EOL care and changes to current practice that they support. The high response rate to this question, as well as the frequency of multiple recommendations from emergency nurses, indicate that many components of EOL care have the potential to be improved. Study participants' clearly defined recommendations for changes to improve the ED EOL care should be considered for quality improvement initiatives and future research.

The ENA position statement regarding staffing and productivity in the emergency department, which was developed in 1987 and revised in 2011, recognizes that emergency nurse workloads often are too high to adequately care for dying patients and their families. ${ }^{15}$ Variables that affect the consumption of nursing time and resources, along with staffing that is not based solely on nurse to patient ratios, are important factors for consideration when caring for EOL patients in the emergency department. ${ }^{15}$ The number of responses that recommended improvements in this aspect of ED EOL care suggests that previous efforts have been ineffective and that new strategies to improve $\mathrm{RN}$ availability to the dying patient and their loved ones must be implemented.

The frequency of suggestions regarding improved management of family presence at the EOL is congruent with previously published data that indicates that patients and family members desire to be together at the EOL, even when CPR or invasive procedures are in progress. ${ }^{16-18}$ Suggestions directed at improving this component of EOL care supports findings that $74 \%$ of emergency nurses requested written policies regarding family presence and 96\% supported additional education for ED staff regarding benefits of family-witnessed resuscitation. ${ }^{18}$ Family presence has been shown to facilitate a sense of patient and family connectedness; it also allows family members to directly convey support and helps facilitate the grieving process. ${ }^{16}$ The ENA position statement on family presence during resuscitation in the emergency department notes that family presence should be offered to family members and that patients would prefer to have a family member present during resuscitation. ${ }^{19}$ Further, a more recent research report also demonstrated that family presence during resuscitations does not have a negative impact on patient care and that it benefits family members. ${ }^{20}$

Emergency nurse responses reiterate the need to improve the level of comfort provided to the patient and family during this important part of life. Currently no ideal EOL or palliative care models exist for emergency nurses to 
guide their care. ${ }^{10}$ Making changes to the ED design and processes to facilitate improved care for dying patients might be possible in the future; however, an immediate modification to current practice is early initiation of palliative care through improved staff training and early referral to palliative care professionals. One study that evaluated an out-of-hospital setting covering more than 47 million people showed that fewer than $6 \%$ of the emergency medical systems had protocols for palliative care or the relief of symptoms or suffering. ${ }^{21}$ An additional study showed that more than $68 \%$ of patients receiving palliative care would have liked to have had this option offered earlier in their disease process, with no patients reporting a desire to delay palliative care until later in the disease process. ${ }^{22}$

\section{Strengths and Limitations}

This study adds to the body of knowledge regarding EOL care in emergency departments. The national random sample was large with a good response rate. However, responses were only obtained from nurses who were members of ENA and therefore can be generalized only to emergency nurses who are members of ENA. Some responses were not legible or did not make sense grammatically and therefore could not be coded into a specific theme.

\section{Future Research}

Future research needs to continue to define and then address the obstacles that surround caring for dying patients in emergency departments. Families need to have a voice in describing and suggesting needed improvements. Research into ways to educate the public regarding all aspects of EOL care may also help improve outcomes.

\section{Implications for Emergency Nurses}

It is hoped that the results of this study and the recommendations identified by emergency nurses will help facilitate changes in the quality of ED EOL care and further the discussion regarding care for dying ED patients. Realistic changes include finding methods to redistribute emergency nurse workloads to increase the amount of direct care to the dying patient and his or her family. Other implications would be to support managers in developing or updating policies regarding family presence during EOL and resuscitation and improving awareness through community education. Modification to ED design in order to improve privacy and comfort for the patient and family may be a long term and expensive change; however, emergency nurses should evaluate their individual departments and identify potential changes in department layout, patient flow, or treatment that could improve these aspects of care without requiring expensive structural changes.

\section{Conclusion}

Large numbers of patients die in emergency departments in the United States every year. Caring for those who are dying in emergency departments is difficult because these highly technical departments were primarily created to save lives. Nevertheless, emergency departments will continue to be one of the primary access points where dying patients receive medical and nursing care. Emergency nurses care for dying patients on a daily basis and are witnesses to both the obstacles and helpful behaviors surrounding EOL care in emergency departments. Implementing changes based on emergency nurse recommendations may dramatically improve EOL care for dying patients and their family members.

\section{REFERENCES}

1. Pitts SR, Niska R, Xu J, Burt CW. National Hospital Ambulatory Care Survey: 2006 Emergency Department Summary. Hyattsville, MD: National Center for Health Statistics; 2006. National Health Statistics Report 7.

2. Emergency Nurses Association. Position statement: end-of-life care in the emergency department. Des Plaines, IL. http://www.ena.org/ about/position/position/Pages/Default.aspx. Accessed January 14, 2011.

3. Centers for Disease Control and Prevention. National Hospital Ambulatory Medical Care Survey: 2008 Emergency Department Summary Tables, tables 1, 4, 13, 23 (/nchs/data/ahcd/nhames_emergency/ nhamsced2008.pdf). Available at: http:/www.cdc.gov/nchs/fastats/ ervisits.htm. Accessed March 29, 2012.

4. Lawson BJ, Burge FI, McIntyre P, Field S, Maxwell D. Palliative care patients in the emergency department. J Palliat Care. 2008;24:247-55.

5. Iserson KV. Withholding and withdrawing medical treatment: an emergency medicine perspective. Ann Emerg Med. 1996;28:51-4.

6. Beckstrand RL, Smith MD, Heaston S, Bond AE. Emergency nurses' perceptions of size, frequency, and magnitude of obstacles and supportive behaviors in end-of-life care. J Emerg Nurs. 2008;34:290-300.

7. Heaston S, Beckstrand RL, Bond AE, Palmer SP. Emergency nurses' perceptions of obstacles and supportive behaviors in end-of-life care. J Emerg Nurs. 2006;32:477-85.

8. McClain K, Perkins P. Terminally ill patients in the emergency department: a practical overview of end-of-life issues. J Emerg Nurs. 2002; 28:515-22

9. LeConte P, Baron D, Trewick D, et al. Withholding and withdrawing life-support therapy in an emergency department: prospective survey. Intensive Care Med. 2004;30:2216-21.

10. Chan GK. End-of-life models and emergency department care. Acad Emerg Med. 2004;11:79-86.

11. Quest TE, Franks NM. Vulnerable populations: cultural and spiritual direction. Emerg Med Clin North Am. 2006;24(3):687-702.

12. Li SP, Chan CW, Lee DT. Helpfulness of nursing actions to suddenly bereaved family members in an accident and emergency setting in Hong Kong. J Adv Nurs. 2002;40:170-80. 
13. Brod M, Tesler LE, Christensen TL. Qualitative research and content validity: developing best practices based on science and experience. Qual Life Res. 2009;18:1263-78.

14. Tashakorri A, Teddlie C. Concurrent triangulation method design. In: JW Creswell, VLP Clark, WE Hanson, eds. Handbook of Mixed Methods in Social and Behavioral Research. Thousand Oaks, CA: Sage; 2003:209-40.

15. Emergency Nurses Association. Position statement: staffing and productivity in the emergency department. http://www.ena.org/about/position/ position/Pages/Default.aspx. Accessed January 23, 2011.

16. Meyers TA, Eichhorn DJ, Guzzetta CE. Do families want to be present during CPR? A retrospective study J Emerg Nurs. 1998;24:400-5.

17. MacLean SL, Guzzetta CE, White C, et al. Family presence during cardiopulmonary resuscitation and invasive procedures: practices of critical care and emergency nurses. Am J Crit Care. 2003;12:246-57.
18. Madden E, Condon C. Emergency nurses' current practices and understanding of family presence during CPR. J Emerg Nurs. 2007;33: 433-40.

19. Emergency Nurses Association. Position statement: family presence during invasive procedures and resuscitation in the emergency department. http://www.ena.org/about/position/position/Pages/Default.aspx. Accessed January 13, 2012.

20. Oman S, Duran C.R. Health care providers' evaluations of family presence during resuscitation. J Emerg Nurs. 2010;36(6):524-33.

21. Quest TE, Marco CA, Derse AR. Hospice and palliative medicine: new subspecialty, new opportunities. Ann Emerg Med. 2008;54:94-102.

22. Rabow MW, Schanche K, Petersen J, Dibble SL, McPhee SJ. Patient perceptions of an outpatient palliative care intervention: "It had been on my mind before, but I did not know how to start talking about death." J Pain Symptom Manage. 2003;26:1010-5. 